\title{
The Solitary Pulmonary Nodule
}

\author{
Dominik Harzheim Ralf Eberhardt Hans Hoffmann Felix J.F. Herth
}

Thoraxklinik am Universitätsklinikum Heidelberg, Heidelberg, Germany

\section{Key Words}

Solitary pulmonary nodule $\cdot$ Lung cancer $\cdot$ Screening . Management $\cdot$ Biopsy $\cdot$ Surgical approaches

\begin{abstract}
Due to the high etiological diversity and the potential for malignancy, pulmonary nodules represent a clinical challenge, becoming increasingly frequent as the number of CT examinations rises. The topic gains even more importance as clear evidence for the effectiveness of CT screening was provided by the National Lung Screening Trial (NLST). Yet, the results were tempered by the high false-positive rate and the requirement of performing further diagnostic procedures. The management of those detected solitary pulmonary nodules is currently based on the individuals' risk of developing lung cancer, the pulmonary nodule characteristics and the capability of diagnostic and therapeutic approaches.
\end{abstract}

(c) 2015 S. Karger AG, Basel

\section{Introduction}

A solitary pulmonary nodule (SPN) is defined as a round or oval opacity smaller than $3 \mathrm{~cm}$ in diameter that is completely surrounded by pulmonary parenchyma (fig. 1) with no other pulmonary abnormalities present. In contrast, pulmonary lesions with a diameter larger than $3 \mathrm{~cm}$ are classified as pulmonary masses and differ from SPN due to their higher likelihood of being malignant [1$3]$. Owing to the high etiological diversity and the potential for malignancy, SPN represent a clinical challenge, which becomes increasingly frequent as the number of CT examinations rises. The workup of these nodules is rather expensive and emotionally burdensome, especially when the patient has risk factors for bronchial carcinoma. SPN are noted in up to $0.2 \%$ of chest radiographs $[4,5]$, whereas $27.3 \%$ of patients undergoing the National Lung Screening Trial (NLST) had at least one SPN with a diameter $>4$ $\mathrm{mm}$ on their CT examination [6]. Differential diagnosis is extensive, but the majority of the identified nodules are comprised of granulomas, lung cancers and hamartomas $[7,8]$. Against the background of potential malignancy and the poor prognosis of advanced lung cancer, rapid identification and resection of malignant SPN is crucial, leading to a 5 -year survival rate of $60-80 \%$ in stage I [ 9 , 10] non-small-cell lung carcinoma (NSCLC). Nonetheless, even in a population at high-risk for lung cancer, the vast majority of small SPN are benign. In the lung screening study of the National Cancer Institute, the lung cancer diagnosis rates were $<5,21.3$ and $34.5 \%$ for nodules $<10$, 11-19 and $>20 \mathrm{~mm}$ in diameter, respectively [11]. The management of an SPN should aim to identify malignancy as fast as possible in order to provide the option of potentially curative surgical treatment whilst avoiding invasive diagnostic procedures in the case of benign lesions. Numerous articles have been published addressing the optimal strategy of evaluating individuals with lung nodules, including the most recently published ACCP guideline for the diagnosis and management of lung cancer [12]. Those strategies are generally based on the individual's risk of developing lung cancer, the pulmonary nodule characteristics and the capability of the current diagnostic and therapeutic approaches.

\section{KARGER 125}

C 2015 S. Karger AG, Basel

0025-7931/15/0902-0160\$39.50/0 


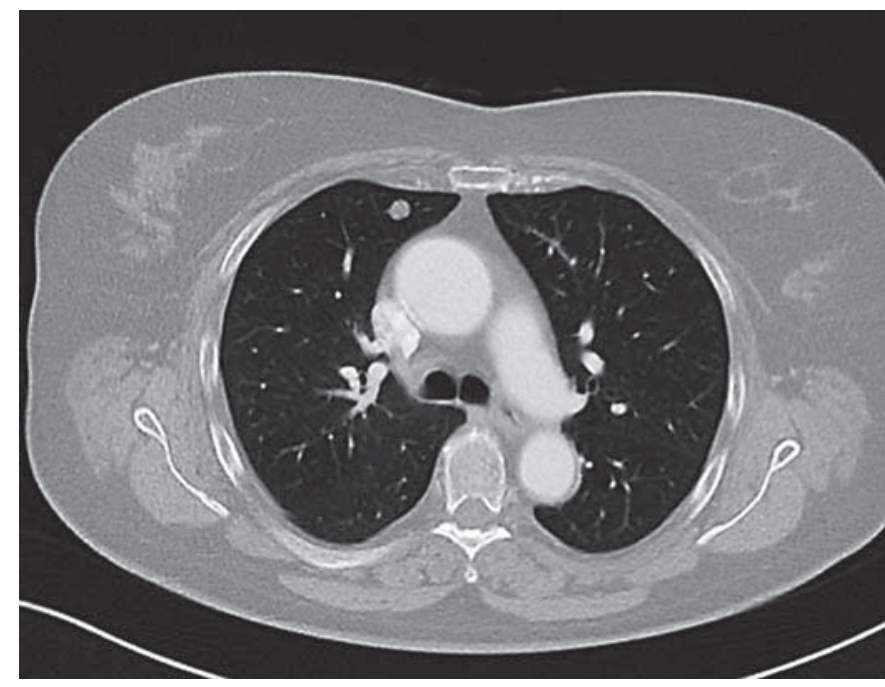

Fig. 1. CT scan of a pulmonary nodule measuring $9 \mathrm{~mm}$ in diameter.

\section{Lung Cancer Screening}

Lung cancer is the most commonly diagnosed cancer and the leading cause of cancer death worldwide $[13,14]$. A significant reduction in mortality from lung cancer has been achieved as a result of smoking reduction and smoking cessation [14-16]. Additional improvements in outcome can be achieved by recent advances in lung cancer treatment, e.g. by targeted therapies in patients with epidermal growth factor receptor mutations [17], surgical approaches and the use of stereotactic radiotherapy $[18$, 19].

Nonetheless, lung cancer is still associated with an extremely poor prognosis, accompanied by a current 5 -year survival rate of $16 \%$ [20]. Due to the late development of symptoms, most patients diagnosed with lung cancer already have advanced disease ( $40 \%$ stage IV, $30 \%$ stage III) at the time of diagnosis, resulting in the above-mentioned poor prognosis. Although earlier randomized controlled trials for lung cancer screening involving chest radiographs and sputum cytology were not able to show a reduction in lung cancer deaths [21-25], the appearance of low-dose CT (LDCT) with the ability of detecting small lung nodules has led to the initiation of several LDCT lung cancer screening studies [26-33]. The largest among those studies has been the NLST. The study examined 53,454 persons with high risk for lung cancer and showed promising results with a relative reduction in mortality from lung cancer of $20 \%$ compared to screening by chest radi- ography [6]. Three hundred and twenty participants were needed to screen to prevent 1 lung cancer death. Three of 8 ongoing European trials comparing LDCT screening with no screening did not show a mortality benefit of LDCT screening; even so, none was sufficiently powered to identify a significant mortality benefit $[31,34,35]$.

Based on the strong evidence of the NLST, all current US guidelines recommend lung cancer screening using LDCT. Those recommendations apply mostly to individuals meeting the NLST inclusion criteria with small alterations in 2 cases $[36,37]$. Yet, uncertainty about potential harm and the generalizability of the NLST results exist. Concerns have been raised about potential harm from lung cancer screening, mainly in terms of potential complications from unnecessary procedures done to investigate what are found to be benign, inconsequential nodules.

In the NLST, 4 in 1,000 fewer died from lung cancer. However, in the LDCT arm 25 in 1,000 had a false alarm leading to an invasive procedure, such as bronchoscopy, biopsy or surgery, and 3 in 1,000 had a major complication from such invasive procedures. Predetermined algorithms for nodule assessment can minimize the number of further imaging studies or invasive biopsies to what is truly necessary. In the NELSON and UK Lung Screen (UKLS) trials, prespecified algorithms are used to manage indeterminate nodules, rather than considering all nodules of a specific size as positive, as done in the NLST [38]. Results from these trials will contribute important additional information that could help to better design future screening programs.

The positive aspect of LDCT screening in the postNLST area is obvious and seems to have been even underestimated in terms of the potential extent of mortality reduction. The NLST was designed to test the null hypothesis of no difference in effectiveness between the two types of screening (LDCT vs. chest radiography). Thus, the extent of mortality reduction was potentially diluted by the cessation of screening linked with a prolonged follow-up period [39].

Further improvement of future LDCT screening outcomes might be achieved through modification of the inclusion criteria by means of applying risk stratification models. Even though smoking history and age account for the broad majority of lung cancer risk, other risk factors such as socioeconomic status, family history, occupational exposure, pulmonary fibrosis and COPD also contribute to a higher lung cancer risk profile [40]. Compared to the NLST inclusion criteria, which are solely based on age and smoking history, a recently updated 
lung cancer risk prediction model $\left(\mathrm{PLCO}_{\mathrm{M} 2012}\right)$ showed an improvement in sensitivity (83.0 vs. $71.1 \%, \mathrm{p}<0.001)$ and positive predictive value (PPV; 4.0 vs. $3.4 \%, \mathrm{p}=0.01$ ), without loss of specificity. According to the analysis, $41.3 \%$ fewer lung cancers would have been missed by application of this model, leading to the conclusion that $\mathrm{PLCO}_{\mathrm{M} 2012}$ is more efficient in identifying persons suitable for lung cancer screening than the NLST criteria [41]. The implementation of an accurate model including additional risk factors in order to select appropriate persons for lung cancer screening is likely to be cost-effective and will reduce harm to people with the lowest risk of lung cancer $[38,41]$.

Yet, some unresolved issues and harms are accompanied by LDCT screening. The NLST as well as the ongoing European LDCT screening trials were carried out in particularly experienced centers for lung cancer, leading to results with limited generalizability. Even though current guidelines recommend that lung cancer screening should only take place in qualified centers, the question arises as to what extent the present data are representative of future upcoming screening on a broader scale. Especially in terms of adverse events, the evidence for considerably better outcomes of lung cancer surgery in dedicated centers such as those conducting LDCT trials relativizes the statement concerning the low risk of major complications following a positive screening test in some cases [42]. In the NLST, $1.2 \%$ of patients who finally had benign lesions had undergone an invasive procedure and $0.7 \%$ had had a thoracoscopy, mediastinoscopy or thoracotomy. In the NELSON trial, these numbers were 1.2 and $0.6 \%$, respectively. Mortality from such resections was $1 \%$ in the NLST, which even compares favorably to that reported from high-volume thoracic centers [43]. In low-volume hospitals, mortality of major pulmonary resections ranges from 3 to $5 \%[43,44]$. Consequently, it should be encouraged that uniform standards and highquality controls are implemented prior to screening on a broader scale. In their preliminary decision to cover lung cancer screening, Medicare addressed this point by defining strict eligibility criteria for screening [45].

Still, it is questionable whether the NLST results can be generalized with regard to different health care systems all over Europe. When Heuvers et al. [46] applied the NLST criteria to an ongoing prospective cohort study in the Netherlands, only around $30 \%$ of lung cancer cases that occurred in their cohort met the NLST inclusion criteria. In other words, $70 \%$ of cases would not have been included in this screening trial if based on the NLST inclusion criteria. Thus, a relative reduction of $20 \%$ in the
NLST would correlate with a $6 \%$ reduction of mortality in the Rotterdam study population.

Further aspects of LDCT screening that require careful examination before implementation include radiation exposure, overdiagnosis, potential harm through incidental findings and the possibly negative impact of screening on smoking behavior or quality of life.

The magnitude of potential harm is not entirely conceivable at the moment. Although there are indications that smoking behavior and quality of life are not negatively influenced by LDCT screening [47-49], clinical experience frequently reports that a potentially malignant diagnosis can have a significant impact on the individual's mind [50].

Twenty-four percent of people undergoing NLST screening had 'positive' and therefore potentially malignant results in their baseline CT examination. A total of $96.4 \%$ proved to be false-positive results at a later point of time, highlighting the extent of this issue. While the rate of invasive interventions and severe adverse events in this group was judged to be low [6], at least several follow-up CT scans, accompanied by additional radiation exposure, were necessary to rule out malignancy. Utilization of predetermined algorithms for nodule assessment and application of volumetric CT, as used in the NELSON and UKLS trials may eventually reduce the number of false positives undergoing invasive diagnostic procedures and also assist with the management decisions concerning indeterminate nodules [38]. 3-D volumetric measurements are probably superior to 2-D diameter measurements in terms of accuracy and reproducibility because the whole nodule is analyzed, leading to an improvement of the PPV $[16,51]$. The issue at hand is the low availability of this modern imaging approach to pulmonary nodules.

Overtreatment is of specific concern in lung cancer screening. The data from a recent analysis of the NLST dataset suggest that, at most, $18 \%$ of persons in the LDCT arm with screen-detected lung cancer and $22 \%$ of those in the LDCT arm with screen-detected NSCLC may be cases of overdiagnosis. In other words, if these individuals had not entered the NLST, they would not have received a lung cancer diagnosis or treatment, at least for the next 5 years [52]. This is most striking in patients with a diagnosis of minimally invasive adenocarcinomas, suggesting an indolent behavior and good long-term outcome. These data raise the question as to the necessity and type of therapy required if a diagnosis of minimally invasive adenocarcinoma is established, and challenge the diagnostic community to develop a classification scheme that could accurately phenotype all lung tumors [52]. In a recent 
survey, $51 \%$ of all participants were unprepared to start a screening that results in more than 1 overtreated person per 1 life saved from death due to cancer [53]. The number of cases of overdiagnosis found among the 320 participants who would need to be screened in the NLST to prevent 1 death from lung cancer was 1.38 [52].

Another point concerns radiation exposure. The effective dose of LDCT averages about $1.5 \mathrm{mSv}$ per examination, whereas diagnostic CT ( $8 \mathrm{mSv})$ or positron emission tomography (PET)-CT $(\sim 14 \mathrm{mSv})$, which are applied in order to further investigate those nodules, account for most of the radiation exposure in screening studies. In the NLST, participants received approximately $8 \mathrm{mSv}$ over 3 years of screening. Estimates of harm from such radiation are based on dose extrapolations from atomic bombings and nuclear industry workers. Based on the NLST data, these models predict about 1 cancer death caused by radiation from imaging per 2,500 participants screened. These estimations led to the conclusion that the mortality benefit of LDCT screening obviously outweighs the radiation risk [54]. Nonetheless, a recent analysis of the NLST data found that lung screening participants may experience a cumulative radiation exposure of up to $280 \mathrm{mSv}$ over a 20 -year period and $420 \mathrm{mSv}$ over 30 years of ongoing LDCT screening. This would account for a nontrivial radiation dose, exceeding those of nuclear workers and atomic bomb survivors [55]. The authors came to the conclusion that the radiation exposure of current lung cancer screening protocols could independently increase the risk of lung cancer beyond cigarette smoking if conducted over 20- to 30-year periods [55].

Cost-effectiveness depicts a fundamental requirement of screening implementation. At the moment, estimates regarding LDCT screening vary widely. Depending on the underlying assumptions and models used, lung screening has been judged in a broad margin, ranging from highly cost-effective to not cost-effective [56, 57], unless combined with smoking cessation interventions [58]. A recent analysis of Black et al. [59] estimated the costs per QALY gained to be USD 81,000. They concluded that the calculation was greatly altered by even modest changes in the underlying assumptions and would therefore depend on how screening is implemented outside the trial.

Broad consent exists, however, concerning the implementation of smoking cessation programs into lung cancer screening, which most likely depicts a 'teachable moment' to improve smoking cessation in this heavily smoking population [60-62].

The NLST has provided clear evidence for the effectiveness of CT screening, yet many questions concerning the best possible execution of LDCT screening (e.g. management of lung nodules detected, inclusion criteria, screening duration and length of screening intervals) and reservations towards the above-discussed harms of LDCT screening remain. Based on those concerns, the European academic community is currently restrained with respect to giving recommendations comparable to those that exist in the US. The results of the European NELSON trial and the pooling of the EURACT trials will become available in 2015-2016. Those data will not only provide further mortality data on CT screening but also provide further information about cost-effectiveness, risk stratification and radiological protocols, which will likely reduce the number of false-positive results [16].

\section{Management of SPN}

The best possible management strategy of an SPN is based on clinical experience and on the profound knowledge of different diagnostic approaches, rather than on scientific evidence from controlled trials. To be evaluated by a randomized study, too many factors, such as the individual's risk for developing lung cancer and the respective health status or the radiological characteristics of the lung nodule, affect the optimal management strategy. As a result of upcoming LDCT screening, the optimal way of lung nodule management poses a significant clinical concern. Additionally, an increasing number of lung nodules are detected due to the more frequent implementation of image formatting [63-65] or computer-aided detection software as a 'second reader' $[66-68]$.

When an SPN has been detected, assessment of the nodule's risk for being malignant guides further evaluation. This assessment is based on the radiological characteristics and the patients' individual risk of having lung cancer.

\section{Radiological Evaluation}

The most important predictor for malignancy is nodule size. According to the analysis of NLST baseline results, the PPV for malignancy increased significantly from $1.7 \%$ for nodules $7-10 \mathrm{~mm}$ in diameter to $11.9,29.7$ and $41.3 \%$ for nodules with a diameter of $11-20,21-30$ and $>30 \mathrm{~mm}$, respectively [69].

When assessing the likelihood of malignancy, further image features should be considered. These include calcification as a strong predictor for benign disease (unless presenting in an eccentric pattern) [2,3], as well as detec- 
tion of intranodular fat [70]. Characteristics suggesting malignancy include spiculated and ragged margins [2, 71], vascular convergence [72], air bronchograms and pseudocavitation [71]. True cavitation, particularly when accompanied with a thick and irregular wall, depicts a strong predictor of malignancy. Although benign lesions can also show cavitation, the corresponding wall usually is thinner and smoother (approximately 95\% of lesions with cavity walls thinner than $4 \mathrm{~mm}$ are benign) $[73,74]$. In an analysis of the NELSON trial data, the combination of round shape, smooth margins and low attenuation was $100 \%$ predictive of benignity [75]. Nonetheless, earlier studies have shown that even nodules with smooth margins can be cancerous, with up to one third of malignant lesions having smooth margins $[2,76]$.

CT scan morphology helps to estimate the probability of malignancy, but rarely results in conclusive findings one can rely on without the need for further investigation. The difficulty in predicting which nodule might be malignant is emphasized by the low PPV in screening studies. With a cancer prevalence of $1-2 \%$, the PPV of a nodule actually being malignant, but judged by the radiologist to be 'suspicious', large in size or with a VDT (volume doubling time) $<400$ days, was only around $35 \%$ in 2 studies $[30,77]$. However, the implementation of VDT measurement seems to result in an improvement of the negative predictive value [30].

\section{Pretest Probability}

Evaluating pretest probability enables further selection and interpretation of subsequent diagnostic workup properly. Several quantitative models have been created in order to accurately estimate pretest probabilities. The most extensively validated model is based on the analysis of six independent predictors of malignancy and was developed by investigating 419 patients with noncalcified nodules that measured $4-30 \mathrm{~mm}$ in diameter on chest radiography $[78,79]$. Those independent predictors include older age, current or past smoking history, nodule diameter, history of extrathoracic cancer $>5$ years before nodule detection, spiculation and upper lobe location. Three studies that were investigating the accuracy of those models came to the conclusion that clinical judgment and models appear to have similar accuracy for lung nodule characterization $[5,80,81]$. However, agreement between judgment and the models was modest, suggesting that qualitative and quantitative approaches might provide complementary information.

After assessing the likelihood of malignancy based on radiographic and clinical characteristics, one can decide on the course of further workup. However, before ordering imaging tests or biopsy procedures, an accurate estimation of the individuals' condition and respective perception is inevitable. Obviously a 90 -year-old patient with several comorbidities requires a different approach than a 50-year-old patient in good health. Yet, the sheer mass of recommendations and the scarce time schedule of everyday clinical practice potentially makes us lose grip on patient-centered, individual medicine.

Based on the recommendations of the recently updated ACCP guidelines, further management depends on nodule size with a cutoff value of $8 \mathrm{~mm}$ [12].

\section{Lung Nodules $\leq 8 \mathrm{~mm}$ in Diameter}

Resulting from the extremely low prevalence of malignancy among small lung nodules, being $<1$ and $2.3-6 \%$ for nodules with a diameter of $<5$ and 5-9 mm, respectively $[11,82]$, nodules of this size are normally followed up by LDCT. Risks of both a surgical approach and lung biopsy would outweigh benefit, whereas PET-CT yields unreliable results in small lung nodules [83, 84].

Due to the different probability for malignancy and the different growth rate, lung nodules are further classified into solid, subsolid and pure ground-glass nodules. While most malignant nodules are solid, partly solid nodules are most likely to be cancerous, with $40-50 \%$ being malignant though having a diameter of $<1.5 \mathrm{~cm}[82,85]$. Hence, patients with these nodules should be referred sooner for bioptic or surgical procedures (fig. 1).

In an analysis of growth rates of small lung cancers detected during a 3-year mass-screening program, VDT for ground-glass, subsolid or solid nodules were 813,457 and 149 days, respectively [86]. This fact, as well as uncertainty about sensitivity of needle biopsy and PET scan, high prevalence of premalignant disease, challenges with determining growth on serial CT scans and concerns regarding an increasing incidence of adenocarcinomas in younger and nonsmoking individuals [82], led to new recommendations of the Fleischner Society, solely addressing subsolid nodules [87].

Those recommendations are summarized in table 1 . They weight multiple factors such as nodule size, variable growth rate, clinical risk factors and limited accuracy of available techniques for determining growth. The recommendations only apply to the evaluation of asymptomatic patients with no history of extrathoracic malignancy.

One main concern should be the use of the lowest possible radiation dose in order to minimize cumulative radiation exposure in light of the likelihood of multiple follow-up CT scans. 
Table 1. Recommendations for the management of pulmonary nodules referring to the statements from the Fleischner Society

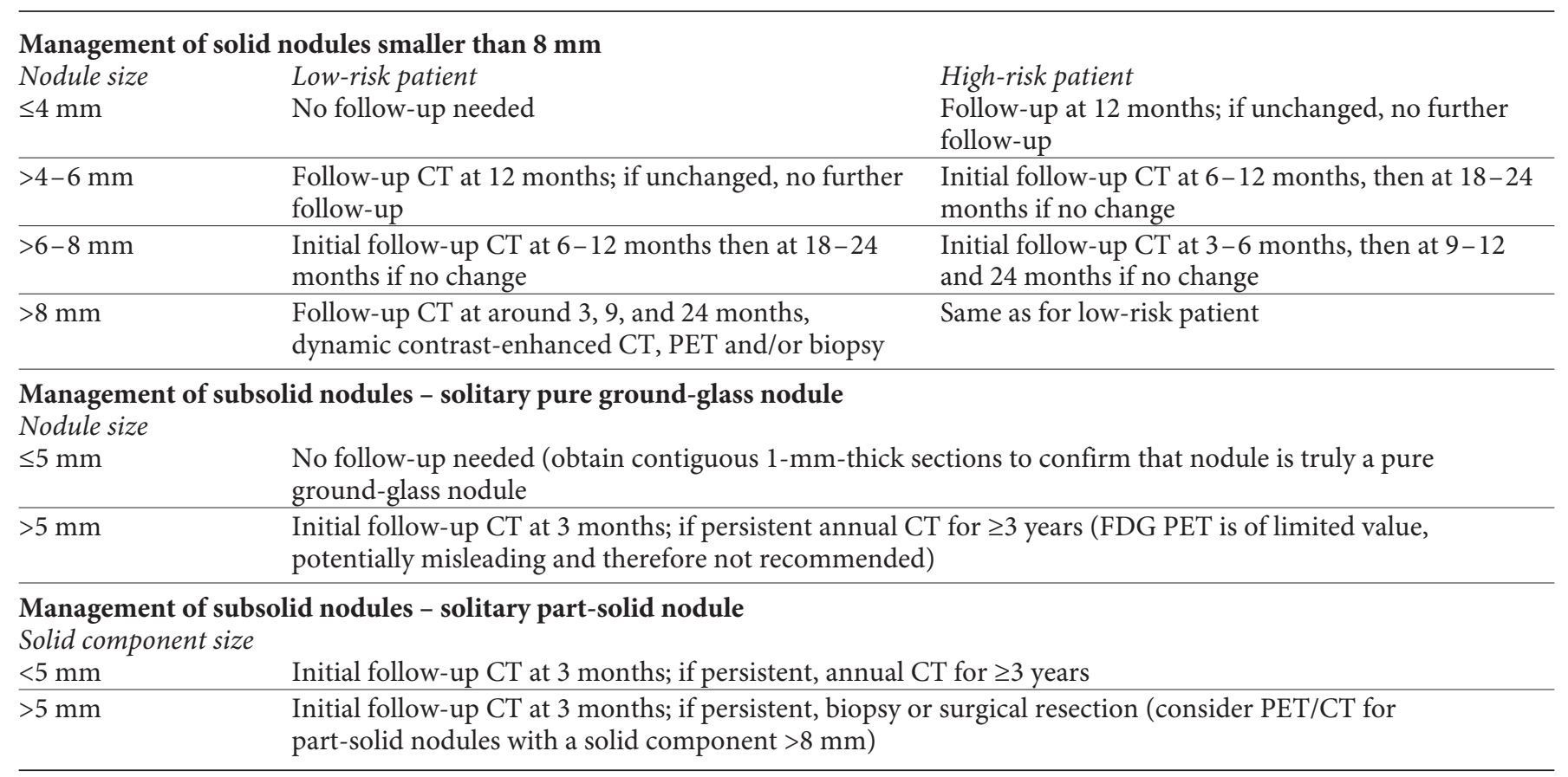

\section{Solid Lung Nodules $>8 \mathrm{~mm}$ in Diameter}

In contrast to small lung nodules, with nodules $>8$ $\mathrm{mm}$, evaluation of cancer probability by functional imaging tests (e.g. PET scan) or bioptic procedures, yields more valid results. Due to the higher probability of malignancy and higher diversity of reasonable diagnostic possibilities, several workup strategies have to be taken into account. A definitive diagnosis and concurrent treatment of malignant nodules is accomplished by surgery. Nevertheless, for patients with benign nodules, this procedure should be avoided. Nonsurgical biopsy can establish a specific benign or malignant diagnosis. However, even a bioptic approach is invasive, potentially accompanied by adverse events, and depending on nodule size often nondiagnostic. CT scan surveillance avoids potential side effects in patients with benign nodules, but delays diagnosis and treatment in cases of malignancy.

A management algorithm, based on the recommendations of the recently updated ACCP guidelines, is presented in figure 2 . After a possible investigation by functional imaging, further management approaches are decided according to the probability of cancer and include either surveillance with serial CT scans, nonsurgical biopsy, or primary surgery. A decision analysis investigating the best possible approach to the initial management of SPN showed that the decision is a 'close call' [88]. In the analysis, a primary surgical approach yielded a slightly longer average life expectancy when the probability of cancer was very high. Needle aspiration biopsy or bronchoscopy had a narrow advantage when the probability of cancer was intermediate. In contrast, serial chest films followed by surgery in case of nodule growth produced slightly longer average life expectancy when the probability of malignancy was very low. As different strategies yield similar results, patients should be encouraged to actively participate in decision making with individual preferences guiding the further workup strategy.

In the following, more details on diagnostic procedures are outlined.

\section{Functional Imaging}

A meta-analysis of 44 studies about PET, single-photon emission CT (SPECT), dynamic CT and dynamic magnetic resonance tomography came to the conclusion that these noninvasive investigations are accurate in distinguishing malignant from benign SPN [89]. Sensitivity ranged from 93\% for dynamic CT to 95\% for both PET and SPECT scans, whereas specificity ranged from $76 \%$ for dynamic CT to $82 \%$ for PET/SPECT scans. The ability to provide additional information about lung cancer staging gives PET scanning an advantage over alternative functional imaging techniques. Though yielding good re- 


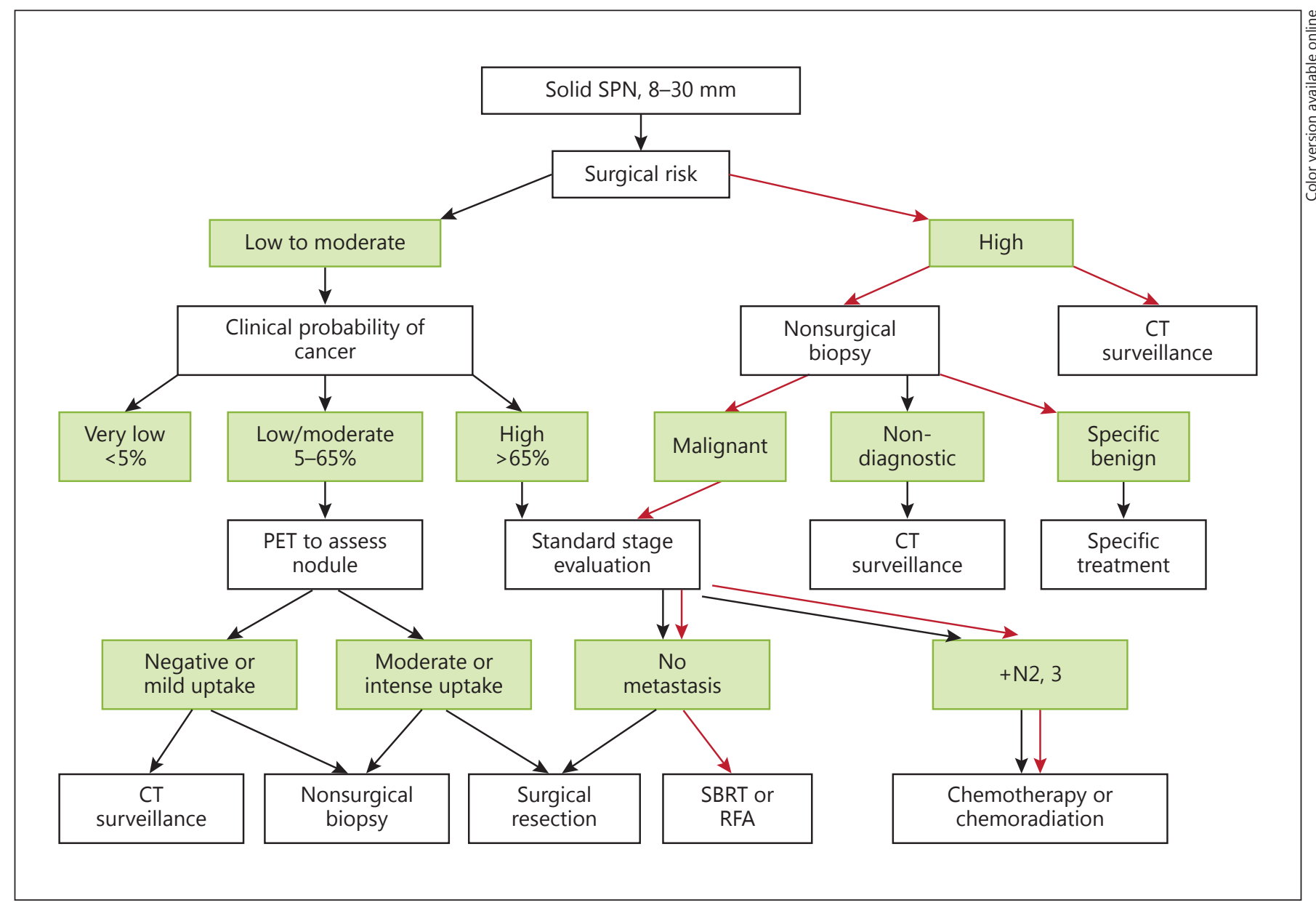

Fig. 2. Management algorithm for individuals with solid nodules measuring $8-30 \mathrm{~mm}$ in diameter. SBRT $=$ Stereotactic body radiotherapy.

sults for sensitivity, a negative PET scan result does not reliably exclude malignancy when investigating patients with a high pretest probability. Hence, those patients with a negative PET scan result should be either followed up by serial CT scans or referred for needle biopsy in order to confirm benignity. Since fluorodeoxyglucose uptake in the primary tumor has been shown to inversely correlate with survival $[90,91]$, patients with a negative PET scan finding show a favorable prognosis although definitive surgical treatment is delayed by a period of observation as long as 238 days $[92,93]$. False-positive PET findings often represent infections or inflammatory conditions, including tuberculosis, mycoses, rheumatoid nodules and sarcoidosis. Accordingly, the current ACCP guidelines make the following recommendation. In the individual with a solid, indeterminate nodule that measures $>8 \mathrm{~mm}$ in diameter and low to moderate pretest probabil- ity of malignancy (5-65\%), functional imaging, preferably with PET, should be performed to characterize the nodule (grade 2C). However, functional imaging should not be performed in the individual with a solid, indeterminate nodule and a high pretest probability of malignancy [12].

\section{Nonsurgical Biopsy}

For SPN with a diameter $>8 \mathrm{~mm}$, invasive diagnosis or surgery is recommended, except when the probability of cancer is very low [12, 94, 95]. Nonsurgical biopsy by transthoracic needle biopsy (TTNB) or bronchoscopy is the procedure of choice in individuals with a high surgical risk and when imaging results and pretest probability are discordant and probability of malignancy is low to moderate [12]. However, even for patients with several comorbidities and a high risk for surgical complications and for 
Fig. 3. Pulmonary nodule sampled by fluoroscopic guided bronchoscopy.
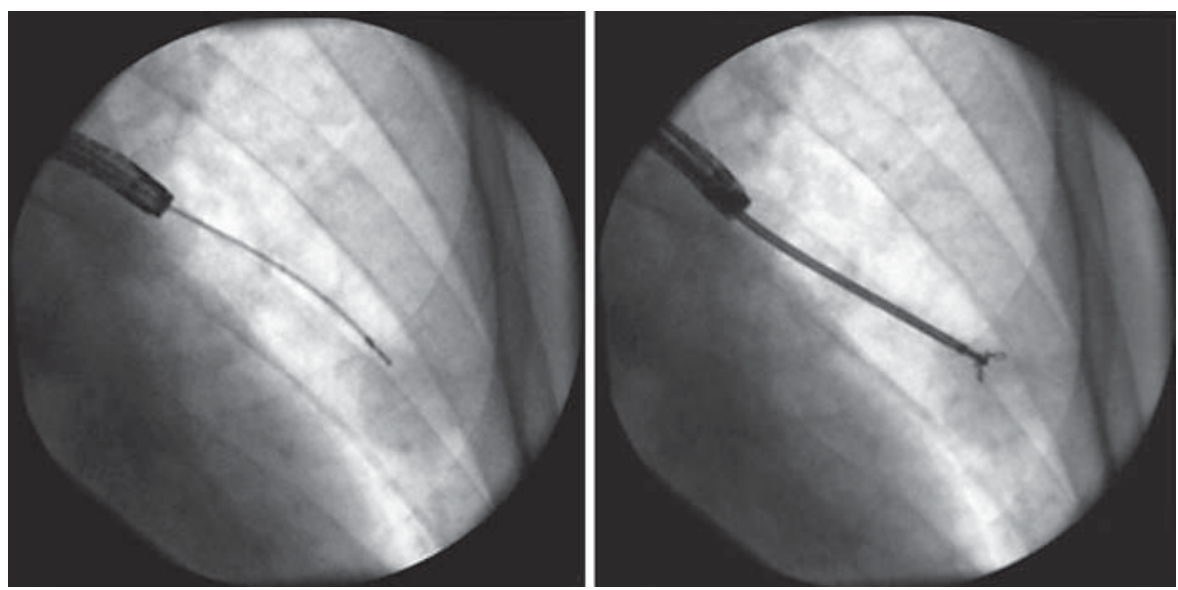

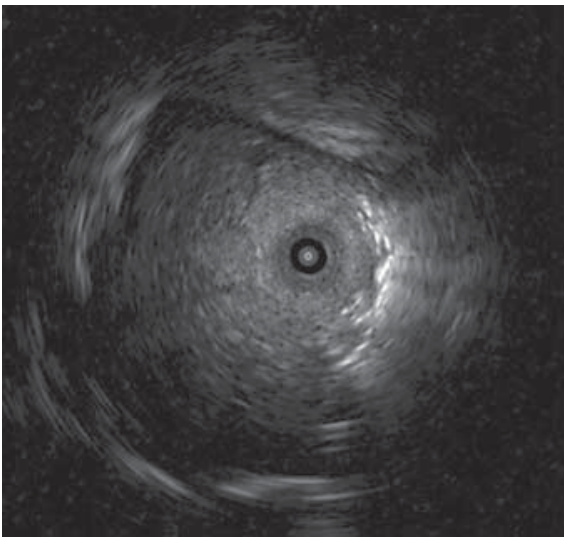

Fig. 4. EBUS displays a pulmonary nodule.

patients who desire proof of malignancy prior to surgery, nonsurgical biopsy should be recommended. The optimal approach to SPN is to surgically resect all malignant nodules while sparing the benign ones. Yet, in many cases, one deals with inoperable patients, accounting for $73 \%$ of individuals diagnosed with an SPN in one study [96].

For identifying malignancy in a high-prevalence population, TTNB yields high sensitivity values around $90 \%$, with a slightly lower sensitivity of $68-78 \%$ for smaller lesions ( $\leq 15 \mathrm{~mm}$ in diameter) $[97,98]$. Sensitivity drops further with increasing distance between the nodule and pleura $[99,100]$. A retrospective study of 114 patients found that the addition of TTNB reduced the frequency of missed surgical cure from 10 to $7 \%$ and reduced the frequency of unnecessary surgery for a benign lesion from 39 to 15\% [101]. Approximately $15 \%$ of patients undergoing TTNB suffer from pneumothorax with $6.6 \%$ requiring chest tube insertion [102]. This depicts a major problem since many of these patients have severe comorbidities like COPD associated with a small cardiopulmonary reserve.

Bronchoscopy, with a risk of $<3 \%$ for pneumothorax, depicts a less invasive approach for diagnosing SPN. Yet, the conventional bronchoscopic approach, composed of transbronchial biopsies under fluoroscopic guidance (fig. 3), yields relatively low sensitivity scores for peripheral small nodules. Sensitivity averages around 34 and $63 \%$ for nodules with a diameter of $<2$ and $>2 \mathrm{~cm}$, respectively [103]. Besides size, diagnostic yield depends on the location of the lesion, fluoroscopic visibility, biopsy method (forceps biopsy 57\%, brush 54\%, wash 43\%), number of biopsies taken and the presence of an air bronchogram, providing a road map to the bronchial lesion [104-106].

In order to achieve better results in diagnosing smaller SPN, several innovative navigation methods have recently been developed. Those include endobronchial ultrasound (EBUS), guide-sheath, ultrathin bronchoscopy, virtual bronchoscopy (VBN) and electromagnetic navigation (ENB). EBUS enables the investigator to visualize peripheral lesions through different ultrasound absorption characteristics of lung tissue and solid structures. The ultrasound transducer is advanced through the working channel of the bronchoscope and provides a $360^{\circ} \mathrm{ul}-$ trasonic view of small airways and surrounding tissue (fig. 4). It has significantly enhanced the bronchoscopic diagnostic yield for small pulmonary nodules [107-109] and can be used in combination with other navigation modalities like fluoroscopy or ENB. Particularly for small nodules $<25 \mathrm{~mm}$, EBUS shows promising results with a pooled sensitivity of $71 \%$ across 7 studies enrolling 580 patients [12]. When used in combination with ENB, a 
study could demonstrate a higher diagnostic yield for the combined procedure (88\%) than for EBUS-transbronchial biopsy (EBUS-TBB; 69\%) or ENB (59\%) alone. ENB uses technology similar to a car GPS (global positioning system) and provides navigational assistance coupled with steering ability to localize and sample pulmonary nodules. A sensor, located at the tip of the steerable catheter, is accurately localized through an electromagnetic field. With the aid of reconstructed CT scan data, a pulmonary nodule can be tracked, visualized and sampled [110]. The diagnostic yield of ENB-guided TBB for nodules $<2 \mathrm{~cm}$ ranged from 44 to $75 \%$ (median, 68.5\%) [12]. A similar technology is VBN. It uses data derived from CT scans to simulate a virtual endobronchial pathway to the pulmonary nodule, thus facilitating bronchoscopic navigation. New bronchoscopic approaches to accessing lesions in the lung parenchyma are being investigated [111].

A recent meta-analysis identified 39 studies using novel bronchoscopic guiding technologies such as EBUS, ENB, VBN, guide sheath and ultrathin bronchoscopy showed a pooled diagnostic yield of $70 \%$ [112]. For nodules measuring $\leq 2 \mathrm{~cm}$ in diameter, the diagnostic yield was $61 \%$, which is substantially higher than conventional bronchoscopy (34\%). However, studies were limited by low scores for study quality, inconsistent results and the indirectness that characterizes most studies of diagnostic accuracy [12].

Even though novel bronchoscopic guiding technologies do not provide a sensitivity as high as that of TTNB, the preferable side effect profile favors a bronchoscopic approach to pulmonary nodules. The choice between bronchoscopy and TTNB should be based on clinical and radiological features of individual patients. For example, radiological findings may predict a lower diagnostic yield of EBUS-TBB (e.g. SPN in apicoposterior bronchial segments [113], pleural-based lesions and subpleural lesions $[114,115])$ or a higher risk for complications with TTNB (e.g. perihilar-located lesions, emphysema or lesion size $[114,116])$.

In case of nondiagnostic results, it is important to realize that neither TTNB nor bronchoscopic biopsy rules out malignancy.

\section{Therapy}

The gold standard for diagnosis and definitive treatment of malignant nodules remains surgical resection, while benign nodules usually undergo conservative treatment. After considering surgical risk and benefits of definitive diagnosis and treatment, lung nodules are preferentially approached by thoracoscopic wedge resection. If a nodule proves to be malignant, lobectomy and systematic sampling of mediastinal lymph nodes are the standard of care for complete oncological resection and staging [94]. Thoracoscopic lobectomy is accompanied by 30 -day mortality below $2 \%$ [117]. Sublobar resection is only recommended for individuals with a poor cardiac performance or limited pulmonary reserve since the risk for locoregional recurrence is increased [118, 119].

In case of functional inoperability, therapeutic alternatives include external beam radiation therapy (EBRT) and percutaneous image-guided radiofrequency ablation (RFA). Newer techniques of EBRT like intensitymodulated radiation therapy or stereotactic body radiation therapy allow a more accurate therapy while lowering the radiation exposure to nearby healthy tissues. Local tumor control by EBRT can be achieved in about $70-100 \%$ with a 2 -year survival rate of $22-72 \%$ being reported in stage I/II NSCLC $[94,120]$.

RFA is a minimally invasive technique with the ability to produce large volumes of coagulation necrosis in a controlled fashion. A prospective multicenter study could show a complete response of target tumors lasting at least 1 year in $88 \%$ of cases and 1 -year overall survival of $70 \%$ [121]. However, like TTNB, the percutaneous approach was accompanied by an increased rate of complications like pneumothorax and airway bleeding.

Bronchoscopic treatment approaches are under development. In order to enhance the accuracy of EBRT, so-called 'fiducials' can be placed under ENB or EBUS guidance [122-124]. Furthermore, endoluminal brachytherapy is being investigated [125].

Another treatment approach represents bronchoscopic RFA. After proving the safety, feasibility and effectivity of bronchoscopy-guided RFA in an animal study [126], Tanabe et al. [127] conducted a study enrolling 10 patients with NSCLC stage IA. The histological analysis after definitive surgical resection revealed vital tumor cells around the necrotic tissue, indicating a yet insufficient ablation effect. However, the authors of the study assume to achieve a larger and thus sufficient coagulation effect through increase of power output, making it a potential therapeutic approach for medically inoperable patients with stage I NSCLC in the future. 


\section{Conclusion}

SPN are detected more frequently with the aid of improved imaging techniques. This depicts a major clinical and socioeconomic challenge. Since the NLST has provided compelling evidence of the efficacy of low-dose CT screening by showing a reduction of lung cancer mortality, screening is being recommended by an increasing number of national guidelines. Results of several European LDCT trials are awaited in the near future and will hopefully shed light on some of the open questions regarding this topic. The CT scan morphology of pulmonary nodules often enables us to estimate the probability of malignancy, but rarely results in reliable and conclu- sive findings. Further management of detected pulmonary nodules is primarily based on nodule size, pretest probability of malignancy and the aforementioned radiological morphology. Besides sequential follow-up investigations by LDCT and definite diagnosis through surgery, nonsurgical biopsy is often the chosen way of diagnosing pulmonary nodules. Until recently, TTNB has been the method of choice when assessing small pulmonary nodules nonsurgically. However, the development of more sophisticated ways of bronchoscopic sampling makes this method an important alternative. The rapid progress in these bronchoscopic techniques will aid in the quick determination of malignancy of these nodules.

\section{References}

1 Tammemagi MC, Freedman MT, Pinsky PF, Oken MM, Hu P, Riley TL, et al: Prediction of true positive lung cancers in individuals with abnormal suspicious chest radiographs: a prostate, lung, colorectal, and ovarian cancer screening trial study. J Thorac Oncol 2009;4: 710-721.

-2 Siegelman SS, Khouri NF, Leo FP, Fishman EK, Braverman RM, Zerhouni EA: Solitary pulmonary nodules: CT assessment. Radiology 1986;160:307-312.

-3 Zerhouni EA, Stitik FP, Siegelman SS, Naidich DP, Sagel SS, Proto AV, et al: CT of the pulmonary nodule: a cooperative study. Radiology 1986;160:319-327.

4 Holin SM, Dwork RE, Glaser S, Rikili AE, Stocklen JB: Solitary pulmonary nodules found in a community-wide chest roentgenographic survey; a five-year follow-up study. Am Rev Tuberc 1959;79:427-439.

5 Swensen SJ, Silverstein MD, Edell ES, Trastek VF, Aughenbaugh GL, Ilstrup DM, et al: Solitary pulmonary nodules: clinical prediction model versus physicians. Mayo Clin Proc 1999;74:319-329.

-6 National Lung Screening Trial Research Team, Aberle DR, Adams AM, Berg CD, Black WC, Clapp JD, Fagerstrom RM, Gareen IF, Gatsonis C, Marcus PM, Sicks JD, et al: Reduced lung-cancer mortality with low-dose computed tomographic screening. N Engl J Med 2011;365:395-409.

7 Murthy SC, Rice TW: The solitary pulmonary nodule: a primer on differential diagnosis. Semin Thorac Cardiovasc Surg 2002;14:239249.

8 Bateson EM: An analysis of 155 solitary lung lesions illustrating the differential diagnosis of mixed tumours of the lung. Clin Radiol 1965;16:51-65.
9 Rami-Porta R, Bolejack V, Goldstraw P: The new tumor, node, and metastasis staging system. Semin Respir Crit Care Med 2011;32: 44-51.

10 Tanoue LT, Detterbeck FC: New TNM classification for non-small-cell lung cancer. Expert Rev Anticancer Ther 2009;9:413-423.

11 Gohagan J, Marcus P, Fagerstrom R, Pinsky P, Kramer B, Prorok P: Baseline findings of a randomized feasibility trial of lung cancer screening with spiral CT scan versus chest radiograph: The Lung Screening Study of the National Cancer Institute. Chest 2004;126: 114-121.

12 Gould MK, Donington J, Lynch WR, Mazzone PJ, Midthun DE, Naidich DP, et al: Evaluation of individuals with pulmonary nodules: when is it lung cancer? Diagnosis and management of lung cancer, 3rd ed: American College of Chest Physicians evidencebased clinical practice guidelines. Chest 2013; 143:e93S-e120S.

13 Ferlay J, Shin H-R, Bray F, Forman D, Mathers C, Parkin DM: Estimates of worldwide burden of cancer in 2008: GLOBOCAN 2008. Int J Cancer 2010;127:2893-2917.

14 Jemal A, Siegel R, Xu J, Ward E: Cancer Statistics, 2010. CA Cancer J Clin 2010;60:277300.

15 Godtfredsen NS, Prescott E, Osler M: Effect of smoking reduction on lung cancer risk. JAMA 2005;294:1505-1510.

16 Field JK, Oudkerk M, Pedersen JH, Duffy SW: Prospects for population screening and diagnosis of lung cancer. Lancet 2013;382:732-741.

-17 Zhou C, Wu Y-L, Chen G, Feng J, Liu X-Q, Wang $C$, et al: Erlotinib versus chemotherapy as first-line treatment for patients with advanced EGFR mutation-positive non-smallcell lung cancer (OPTIMAL, CTONG-0802): a multicentre, open-label, randomised, phase 3 study. Lancet Oncol 2011;12:735-742.
18 Vallières E, Peters S, Van Houtte P, Dalal P, Lim E: Therapeutic advances in non-small cell lung cancer. Thorax 2012;67:1097-1101.

19 Van Baardwijk A, Tomé WA, van Elmpt W, Bentzen SM, Reymen B, Wanders R, et al: Is high-dose stereotactic body radiotherapy (SBRT) for stage I non-small cell lung cancer (NSCLC) overkill? A systematic review. Radiother Oncol 2012;105:145-149.

20 Howlader N, Noone AM, Garshell J, Neyman N, Altekruse SF, Kosary CL, et al: SEER Cancer Statistics Review, 1975-2010. Bethesda, National Cancer Institute, 2013.

21 Tockman MS: Survival and mortality from lung cancer in a screened population: The Johns Hopkins Study. Chest 1986;89:324S$325 \mathrm{~S}$.

22 Tockman MS, Mulshine JL: Sputum screening by quantitative microscopy: a new dawn for detection of lung cancer? Mayo Clin Proc 1997;72:788-790.

23 Payne PW, Sebo TJ, Doudkine A, Garner D, MacAulay C, Lam S, et al: Sputum screening by quantitative microscopy: a reexamination of a portion of the National Cancer Institute Cooperative Early Lung Cancer Study. Mayo Clin Proc 1997;72:697-704.

24 Melamed MR: Lung cancer screening results in the National Cancer Institute New York study. Cancer 2000;89:2356-2362.

25 Fontana RS, Sanderson DR, Woolner LB, Taylor WF, Miller WE, Muhm JR: Lung cancer screening: the Mayo program. J Occup Med 1986;28:746-750

26 Pastorino U, Bellomi M, Landoni C, De Fiori E, Arnaldi P, Picchio M, et al: Early lung-cancer detection with spiral CT and positron emission tomography in heavy smokers: 2-year results. Lancet 2003;362:593-597. 
-27 Infante M, Lutman FR, Cavuto S, Brambilla G, Chiesa G, Passera E, et al: Lung cancer screening with spiral CT: baseline results of the randomized DANTE trial. Lung Cancer 2008;59:355-363.

28 Blanchon T, Bréchot J-M, Grenier PA, Ferretti GR, Lemarié E, Milleron B, et al: Baseline results of the Depiscan study: a French randomized pilot trial of lung cancer screening comparing low dose CT scan (LDCT) and chest X-ray (CXR). Lung Cancer 2007;58:5058.

29 Lopes Pegna A, Picozzi G, Mascalchi M, Maria Carozzi F, Carrozzi L, Comin C, et al: Design, recruitment and baseline results of the ITALUNG trial for lung cancer screening with low-dose CT. Lung Cancer 2009;64:3440.

-30 Van Klaveren RJ, Oudkerk M, Prokop M, Scholten ET, Nackaerts K, Vernhout R, et al: Management of lung nodules detected by volume CT scanning. N Engl J Med 2009;361 2221-2229.

- 31 Pedersen JH, Ashraf H, Dirksen A, Bach K, Hansen $\mathrm{H}$, Toennesen $\mathrm{P}$, et al: The Danish randomized lung cancer CT screening trial overall design and results of the prevalence round. J Thorac Oncol 2009;4:608-614.

- 32 Becker N, Motsch E, Gross M-L, Eigentopf A, Heussel CP, Dienemann H, et al: Randomized study on early detection of lung cancer with MSCT in Germany: study design and results of the first screening round. J Cancer Res Clin Oncol 2012;138:1475-1486.

-33 Baldwin DR, Duffy SW, Wald NJ, Page R, Hansell DM, Field JK: UK Lung Screen (UKLS) nodule management protocol: modelling of a single screen randomised controlled trial of low-dose CT screening for lung cancer. Thorax 2011;66:308-313.

-34 Infante M, Cavuto S, Lutman FR, Brambilla G, Chiesa G, Ceresoli G, et al: A randomized study of lung cancer screening with spiral computed tomography: three-year results from the DANTE trial. Am J Respir Crit Care Med 2009; 180:445-453.

35 Pastorino U, Rossi M, Rosato V, Marchianò A, Sverzellati N, Morosi C, et al: Annual or biennial CT screening versus observation in heavy smokers: 5-year results of the MILD trial. Eur J Cancer Prev 2012;21:308-315.

-36 Jaklitsch MT, Jacobson FL, Austin JHM, Field JK, Jett JR, Keshavjee S, et al: The American Association for Thoracic Surgery guidelines for lung cancer screening using low-dose computed tomography scans for lung cancer survivors and other high-risk groups. J Thorac Cardiovasc Surg 2012;144:33-38.

37 National Comprehensive Cancer Network ${ }^{\circledR}$ : NCCN Clinical Practice Guidelines in Oncology (NCCN Guidelines ${ }^{\circledR}$ ): Lung Cancer Screening. Version I.2013. http://www.respiratory-thessaly.gr/assets/lung_screening\%20 1.2013.pdf.
Field JK, Hansell DM, Duffy SW, Baldwin DR: CT screening for lung cancer: countdown to implementation. Lancet Oncol 2013;14: e591-e600.

-39 Yankelevitz DF, Smith JP: Understanding the core result of the National Lung Screening Trial. N Engl J Med 2013;368:1460-1461.

40 Youlden DR, Cramb SM, Baade PD: The international epidemiology of lung cancer: geographical distribution and secular trends. J Thorac Oncol 2008;3:819-831.

-41 Tammemägi MC, Katki HA, Hocking WG, Church TR, Caporaso N, Kvale PA, et al: Selection criteria for lung-cancer screening. $\mathrm{N}$ Engl J Med 2013;368:728-736.

42 Wender R, Fontham ETH, Barrera E, Colditz GA, Church TR, Ettinger DS, et al: American Cancer Society lung cancer screening guidelines. CA Cancer J Clin 2013;63:106-117.

43 Lüchtenborg M, Riaz SP, Coupland VH, Lim E, Jakobsen E, Krasnik M, et al: High procedure volume is strongly associated with improved survival after lung cancer surgery. J Clin Oncol 2013;31:3141-3146.

44 Detterbeck FC, Mazzone PJ, Naidich DP, Bach PB: Screening for lung cancer: Diagnosis and management of lung cancer, 3rd ed: American College of Chest Physicians evidence-based clinical practice guidelines. Chest 2013;143:e78S-e92S.

45 Medicare Plans to Cover Lung Cancer Screening. November 10, 2014 (cited December 28, 2014). http://www.medpagetoday.com/HematologyOncology/LungCancer/48501.

46 Heuvers ME, Stricker BH, Aerts JG: Generalizing lung-cancer screening results. $\mathrm{N}$ Engl J Med 2012;366:192-193.

47 Van den Bergh KAM, Essink-Bot M-L, Bunge EM, Scholten ET, Prokop M, van Iersel CA, et al: Impact of computed tomography screening for lung cancer on participants in a randomized controlled trial (NELSON trial). Cancer 2008;113:396-404.

48 Ashraf H, Tønnesen P, Pedersen JH, Dirksen A, Thorsen H, Døssing M: Effect of CT screening on smoking habits at 1-year followup in the Danish Lung Cancer Screening Trial (DLCST). Thorax 2009;64:388-392.

49 Ostroff JS, Buckshee N, Mancuso CA, Yankelevitz DF, Henschke CI: Smoking cessation following CT screening for early detection of lung cancer. Prev Med 2001;33:613-621.

50 Wiener RS, Gould MK, Woloshin S, Schwartz LM, Clark JA: What do you mean, a spot?: a qualitative analysis of patients' reactions to discussions with their physicians about pulmonary nodules. Chest 2013;143:672-677.

- 51 Horeweg N, van der Aalst CM, Vliegenthart R, Zhao Y, Xie X, Scholten ET, et al: Volumetric computed tomography screening for lung cancer: three rounds of the NELSON trial. Eur Respir J 2013;42:1659-1667.

52 Patz EF, Pinsky P, Gatsonis C, Sicks JD, Kramer BS, Tammemägi MC, et al: Overdiagnosis in low-dose computed tomography screening for lung cancer. JAMA Intern Med 2014;174:269.
53 Wegwarth O, Gigerenzer G: Overdiagnosis and overtreatment: evaluation of what physicians tell their patients about screening harms. JAMA Intern Med 2013;173:2086-2087.

54 Bach PB, Mirkin JN, Oliver TK, et al: Benefits and harms of CT screening for lung cancer: a systematic review. JAMA 2012;307:24182429.

55 McCunney RJ, Li J: Radiation risks in lung cancer screening programs: a comparison with nuclear industry workers and atomic bomb survivors. Chest 2014;145:618-624.

56 Villanti AC, Jiang Y, Abrams DB, Pyenson BS: A cost-utility analysis of lung cancer screening and the additional benefits of incorporating smoking cessation interventions. PLoS One 2013;8:e71379.

57 Pyenson BS, Sander MS, Jiang Y, Kahn H, Mulshine JL: An actuarial analysis shows that offering lung cancer screening as an insurance benefit would save lives at relatively low cost. Health Aff (Millwood) 2012;31:770-779.

58 McMahon PM, Kong CY, Bouzan C, Weinstein MC, Cipriano LE, Tramontano AC, et al: Cost-effectiveness of CT screening for lung cancer in the U.S. J Thorac Oncol 2011;6: 1841-1848.

59 Black WC, Gareen IF, Soneji SS, Sicks JD, Keeler EB, Aberle DR, et al: Cost-effectiveness of CT screening in the National Lung Screening Trial. N Engl J Med 2014;371:1793-1802.

60 Cox LS, Clark MM, Jett JR, Patten CA, Schroeder DR, Nirelli LM, et al: Change in smoking status after spiral chest computed tomography scan screening. Cancer 2003;98: 2495-2501.

-61 Townsend CO, Clark MM, Jett JR, Patten CA, Schroeder DR, Nirelli LM, et al: Relation between smoking cessation and receiving results from three annual spiral chest computed tomography scans for lung carcinoma screening. Cancer 2005;103:2154-2162.

-62 Taylor KL, Cox LS, Zincke N, Mehta L, McGuire C, Gelmann E: Lung cancer screening as a teachable moment for smoking cessation. Lung Cancer 2007;56:125-134.

63 Jankowski A, Martinelli T, Timsit JF, Brambilla C, Thony F, Coulomb M, et al: Pulmonary nodule detection on MDCT images: evaluation of diagnostic performance using thin axial images, maximum intensity projections, and computer-assisted detection. Eur Radiol 2007;17:3148-3156.

64 Coakley FV, Cohen MD, Johnson MS, Gonin R, Hanna MP: Maximum intensity projection images in the detection of simulated pulmonary nodules by spiral CT. Br J Radiol 1998; 71:135-140.

65 Kawel N, Seifert B, Luetolf M, Boehm T: Effect of slab thickness on the CT detection of pulmonary nodules: use of sliding thin-slab maximum intensity projection and volume rendering. AJR Am J Roentgenol 2009;192:13241329. 
-66 Armato SG 3rd, Li F, Giger ML, MacMahon $\mathrm{H}$, Sone S, Doi K: Lung cancer: performance of automated lung nodule detection applied to cancers missed in a CT screening program. Radiology 2002;225:685-692.

-67 Yuan R, Vos PM, Cooperberg PL: Computeraided detection in screening CT for pulmonary nodules. AJR Am J Roentgenol 2006;186: 1280-1287.

68 Saba L, Caddeo G, Mallarini G: Computeraided detection of pulmonary nodules in computed tomography: analysis and review of the literature. J Comput Assist Tomogr 2007;31:611-619.

-69 National Lung Screening Trial Research Team, Church TR, Black WC, Aberle DR, Berg CD, Clingan KL, Duan F, Fagerstrom RM, Gareen IF, Gierada DS, Jones GC, Mahon I, Marcus PM, Sicks JD, Jain A, Baum S, et al: Results of initial low-dose computed tomographic screening for lung cancer. N Engl J Med 2013;368:1980-1991.

70 Erasmus JJ, Connolly JE, McAdams HP, Roggli VL: Solitary pulmonary nodules. I. Morphologic evaluation for differentiation of benign and malignant lesions. Radiographics 2000;20:43-58

-71 Zwirewich CV, Vedal S, Miller RR, Müller NL: Solitary pulmonary nodule: high-resolution CT and radiologic-pathologic correlation. Radiology 1991;179:469-476.

- 72 Kishi K, Homma S, Kurosaki A, Motoi N, Kohno T, Nakata K, et al: Small lung tumors with the size of $1 \mathrm{~cm}$ or less in diameter: clinical, radiological, and histopathological characteristics. Lung Cancer 2004;44:43-51.

-73 Woodring JH, Fried AM, Chuang VP: Solitary cavities of the lung: diagnostic implications of cavity wall thickness. AJR Am J Roentgenol 1980;135:1269-1271.

74 Woodring JH, Fried AM: Significance of wall thickness in solitary cavities of the lung: a follow-up study. AJR Am J Roentgenol 1983; 140:473-474.

75 Xu DM, van Klaveren RJ, de Bock GH, Leusveld A, Zhao Y, Wang Y, et al: Limited value of shape, margin and CT density in the discrimination between benign and malignant screen detected solid pulmonary nodules of the NELSON trial. Eur J Radiol 2008;68:347-352.

-76 Seemann MD, Seemann O, Luboldt W, Bonél $\mathrm{H}$, Sittek H, Dienemann H, et al: Differentiation of malignant from benign solitary pulmonary lesions using chest radiography, spiral CT and HRCT. Lung Cancer 2000;29:105-124.

-77 Markowitz SB, Miller A, Miller J, Manowitz A, Kieding S, Sider L, et al: Ability of low-dose helical CT to distinguish between benign and malignant noncalcified lung nodules. Chest 2007;131:1028-1034.

-78 Swensen SJ, Silverstein MD, Ilstrup DM, Schleck CD, Edell ES: The probability of malignancy in solitary pulmonary nodules: application to small radiologically indeterminate nodules. Arch Intern Med 1997;157: 849-855.
9 Herder GJ, van Tinteren H, Golding RP, Kostense PJ, Comans EF, Smit EF, et al: Clinical prediction model to characterize pulmonary nodules: validation and added value of 18F-fluorodeoxyglucose positron emission tomography. Chest 2005;128:2490-2496.

80 Gould MK, Simkovich S, Mestaz PJ, Daniel J, Sanders GD, Silvestri G: Predicting the probability of malignancy in patients with pulmonary nodules: comparison of clinical judgment with two validated models. Am J Respir Crit Care Rev 2012;185:A4425-A4425.

-81 Balekian DAA, Silvestri DGA, Simkovich MSM, Mestaz DPJ, Sanders DGD, Daniel MJ, et al: Accuracy of clinicians and models for estimating the probability that a pulmonary nodule is malignant. 2013 (cited in 2013). http://www.atsjournals.org/doi/ abs/10.1513/AnnalsATS.201305-107OC?pr evSearch $=$ Gould + MK\&searchHistoryK ey=\#.UnnZkiReCcY.

-82 Henschke CI, Yankelevitz DF, Mirtcheva R, McGuinness G, McCauley D, Miettinen OS, et al: CT screening for lung cancer: frequency and significance of part-solid and nonsolid nodules. AJR Am J Roentgenol 2002;178: 1053-1057.

83 Herder GJ, Golding RP, Hoekstra OS, Comans EF, Teule GJ, Postmus PE, et al: The performance of ${ }^{18} \mathrm{~F}$-fluorodeoxyglucose positron emission tomography in small solitary pulmonary nodules. Eur J Nucl Med Mol Imaging 2004;31:1231-1236.

84 Nomori H, Watanabe K, Ohtsuka T, Naruke T, Suemasu K, Kobayashi T, et al: Fluorine 18-tagged fluorodeoxyglucose positron emission tomographic scanning to predict lymph node metastasis, invasiveness, or both, in clinical T1 N0 M0 lung adenocarcinoma. J Thorac Cardiovasc Surg 2004;128: 396-401.

85 Li F, Sone S, Abe H, Macmahon H, Doi K: Malignant versus benign nodules at CT screening for lung cancer: comparison of thin-section CT findings. Radiology 2004; 233:793-798.

86 MacMahon H, Austin JHM, Gamsu G, Herold CJ, Jett JR, Naidich DP, et al: Guidelines for management of small pulmonary nodules detected on CT scans: a statement from the Fleischner Society. Radiology 2005;237:395400.

87 Naidich DP, Bankier AA, MacMahon H, Schaefer-Prokop CM, Pistolesi M, Goo JM, et al: Recommendations for the management of subsolid pulmonary nodules detected at CT: a statement from the Fleischner Society. Radiology 2013;266:304-317.

88 Cummings SR, Lillington GA, Richard RJ: Managing solitary pulmonary nodules. The choice of strategy is a 'close call'. Am Rev Respir Dis 1986;134:453-460.

89 Cronin P, Dwamena BA, Kelly AM, Carlos RC: Solitary pulmonary nodules: meta-analytic comparison of cross-sectional imaging modalities for diagnosis of malignancy. Radiology 2008;246:772-782.
-90 Berghmans T, Dusart M, Paesmans M, Hossein-Foucher C, Buvat I, Castaigne C, et al: Primary tumor standardized uptake value (SUVmax) measured on fluorodeoxyglucose positron emission tomography (FDGPET) is of prognostic value for survival in non-small cell lung cancer (NSCLC): a systematic review and meta-analysis (MA) by the European Lung Cancer Working Party for the IASLC Lung Cancer Staging Project. J Thorac Oncol 2008;3:6-12.

91 Nair VS, Barnett PG, Ananth L, Gould MK; Veterans Affairs Solitary Nodule Accuracy Project Cooperative Studies Group: PET scan 18F-fluorodeoxyglucose uptake and prognosis in patients with resected clinical stage IA non-small cell lung cancer. Chest 2010;137:1150-1156.

92 Cheran SK, Nielsen ND, Patz EF Jr: Falsenegative findings for primary lung tumors on FDG positron emission tomography: staging and prognostic implications. AJR Am J Roentgenol 2004;182:1129-1132.

-93 Marom EM, Sarvis S, Herndon JE 2nd, Patz EF Jr: T1 lung cancers: sensitivity of diagnosis with fluorodeoxyglucose PET. Radiology 2002;223:453-459.

94 Goeckenjan G, Sitter H, Thomas M, Branscheid D, Flentje M, Griesinger F, et al: Prevention, diagnosis, therapy, and follow-up of lung cancer: interdisciplinary guideline of the German Respiratory Society and the German Cancer Society. Pneumologie 2011; 65:39-59.

-95 Lim E, Baldwin D, Beckles M, Duffy J, Entwisle J, Faivre-Finn C, et al: Guidelines on the radical management of patients with lung cancer. Thorax 2010;65(suppl 3):iii1iii27.

96 Gasparini S: Diagnostic management of solitary pulmonary nodule. Eur Respir Monogr 2010;90-108.

97 Kothary N, Lock L, Sze DY, Hofmann LV: Computed tomography-guided percutaneous needle biopsy of pulmonary nodules: impact of nodule size on diagnostic accuracy. Clin Lung Cancer 2009;10:360-363.

$\$ 98$ Ng YL, Patsios D, Roberts H, Walsham A, Paul NS, Chung T, et al: CT-guided percutaneous fine-needle aspiration biopsy of pulmonary nodules measuring $10 \mathrm{~mm}$ or less. Clin Radiol 2008;63:272-277.

$\$ 99$ Priola AM, Priola SM, Cataldi A, Errico L, Di Franco M, Campisi P, et al: Accuracy of CT-guided transthoracic needle biopsy of lung lesions: factors affecting diagnostic yield. Radiol Med (Torino) 2007;112:11421159.

100 Ohno Y, Hatabu H, Takenaka D, Higashino $\mathrm{T}$, Watanabe $\mathrm{H}$, Ohbayashi $\mathrm{C}$, et al: CTguided transthoracic needle aspiration biopsy of small $(<$ or $=20 \mathrm{~mm})$ solitary pulmonary nodules. AJR Am J Roentgenol 2003; 180:1665-1669. 
101 Baldwin DR, Eaton T, Kolbe J, Christmas T, Milne D, Mercer J, et al: Management of solitary pulmonary nodules: how do thoracic computed tomography and guided fine needle biopsy influence clinical decisions? Tho$\operatorname{rax} 2002 ; 57: 817-822$.

102 Wiener RS, Schwartz LM, Woloshin S, Welch HG: Population-based risk of complications following transthoracic needle lung biopsy of a pulmonary nodule. Ann Intern Med 2011;155:137-144.

103 Rivera MP, Mehta AC: Initial diagnosis of lung cancer: ACCP evidence-based clinical practice guidelines (2nd edition). Chest 2007; 132:131S-148S.

104 Ost D, Fein AM, Feinsilver SH: The solitary pulmonary nodule. N Engl J Med 2003;348: 2535-2542.

105 Baaklini WA, Reinoso MA, Gorin AB, Sharafkaneh A, Manian P: Diagnostic yield of fiberoptic bronchoscopy in evaluating solitary pulmonary nodules. Chest 2000; 117:1049-1054.

106 Bandoh S, Fujita J, Tojo Y, Yokomise H, Satoh K, Kobayashi S, et al: Diagnostic accuracy and safety of flexible bronchoscopy with multiplanar reconstruction images and ultrafast Papanicolaou stain: evaluating solitary pulmonary nodules. Chest 2003;124: 1985-1992.

-107 Herth FJF, Ernst A, Becker HD: Endobronchial ultrasound-guided transbronchial lung biopsy in solitary pulmonary nodules and peripheral lesions. Eur Respir J 2002;20: 972-974.

108 Shirakawa T, Imamura F, Hamamoto J, Honda I, Fukushima K, Sugimoto M, et al: Usefulness of endobronchial ultrasonography for transbronchial lung biopsies of peripheral lung lesions. Respir Int Rev Thorac Dis 2004;71:260-268.

109 Kuo C-H, Lin S-M, Chen H-C, Chou C-L, Yu C-T, Kuo H-P: Diagnosis of peripheral lung cancer with three echoic features via endobronchial ultrasound. Chest 2007;132: 922-929.

110 Eberhardt R, Anantham D, Herth F, FellerKopman D, Ernst A: Electromagnetic navigation diagnostic bronchoscopy in peripheral lung lesions. Chest 2007;131:1800-1805.
111 Silvestri GA, Herth FJ, Keast T, Rai L, Gibbs J, Wibowo H, et al: Feasibility and safety of bronchoscopic transparenchymal nodule access in canines: a new real-time imageguided approach to lung lesions. Chest 2014; 145:833-838.

112 Wang Memoli JS, Nietert PJ, Silvestri GA: Meta-analysis of guided bronchoscopy for the evaluation of the pulmonary nodule. Chest 2012;142:385-393.

113 Kurimoto N, Miyazawa T, Okimasa S, Maeda A, Oiwa H, Miyazu Y, et al: Endobronchial ultrasonography using a guide sheath increases the ability to diagnose peripheral pulmonary lesions endoscopically. Chest 2004;126:959-965.

114 Fielding DIK, Robinson PJ, Kurimoto N: Biopsy site selection for endobronchial ultrasound guide-sheath transbronchial biopsy of peripheral lung lesions. Intern Med J 2008;38:77-84.

115 Huang C-T, Ho C-C, Tsai Y-J, Yu C-J, Yang P-C: Factors influencing visibility and diagnostic yield of transbronchial biopsy using endobronchial ultrasound in peripheral pulmonary lesions. Respirology 2009;14:859864.

-116 Heyer CM, Reichelt S, Peters SA, Walther JW, Müller K-M, Nicolas V: Computed tomography-navigated transthoracic core biopsy of pulmonary lesions: which factors affect diagnostic yield and complication rates? Acad Radiol 2008;15:1017-1026.

-117 Boffa DJ, Allen MS, Grab JD, Gaissert HA, Harpole DH, Wright CD: Data from The Society of Thoracic Surgeons General Thoracic Surgery database: the surgical management of primary lung tumors. J Thorac Cardiovasc Surg 2008;135:247-254.

118 Warren WH, Faber LP: Segmentectomy versus lobectomy in patients with stage I pulmonary carcinoma. Five-year survival and patterns of intrathoracic recurrence. J Thorac Cardiovasc Surg 1994;107:1087-1093, discussion 1093-1094.

119 Ginsberg RJ, Rubinstein LV: Randomized trial of lobectomy versus limited resection for T1 N0 non-small cell lung cancer. Lung Cancer Study Group. Ann Thorac Surg 1995;60:615-622, discussion 622-623.
120 Rowell NP, Williams CJ: Radical radiotherapy for stage I/II non-small cell lung cancer in patients not sufficiently fit for or declining surgery (medically inoperable): a systematic review. Thorax 2001;56:628-638.

121 Lencioni R, Crocetti L, Cioni R, Suh R, Glenn D, Regge D, et al: Response to radiofrequency ablation of pulmonary tumours: a prospective, intention-to-treat, multicentre clinical trial (the RAPTURE study). Lancet Oncol 2008;9:621-628.

122 Anantham D, Feller-Kopman D, Shanmugham LN, Berman SM, DeCamp MM, Gangadharan SP, et al: Electromagnetic navigation bronchoscopy-guided fiducial placement for robotic stereotactic radiosurgery of lung tumors: a feasibility study. Chest 2007; 132:930-935.

123 Harley DP, Krimsky WS, Sarkar S, Highfield D, Aygun C, Gurses B: Fiducial marker placement using endobronchial ultrasound and navigational bronchoscopy for stereotactic radiosurgery: an alternative strategy. Ann Thorac Surg 2010;89:368-373, discussion 373-374.

124 Schroeder C, Hejal R, Linden PA: Coil spring fiducial markers placed safely using navigation bronchoscopy in inoperable patients allows accurate delivery of CyberKnife stereotactic radiosurgery. J Thorac Cardiovasc Surg 2010;140:1137-1142.

125 Harms W, Krempien R, Grehn C, Hensley F, Debus J, Becker HD: Electromagnetically navigated brachytherapy as a new treatment option for peripheral pulmonary tumors. Strahlenther Onkol 2006;182:108-111.

126 Tsushima K, Koizumi T, Tanabe T, Nakagawa R, Yoshikawa S, Yasuo M, et al: Bronchoscopy-guided radiofrequency ablation as a potential novel therapeutic tool. Eur Respir J 2007;29:1193-1200.

127 Tanabe T, Koizumi T, Tsushima K, Ito M, Kanda S, Kobayashi T, et al: Comparative study of three different catheters for CT imaging-bronchoscopy-guided radiofrequency ablation as a potential and novel interventional therapy for lung cancer. Chest 2010; 137:890-897. 